DOI 10.37882/2223-2982.2020.06-2.15

\title{
ИНТЕГРАТИВНЫЙ ПОДХОД ПРИ СТАНОВЛЕНИИ УЧЕБНОЙ ЛИТЕРАТУРЫ ДЛЯ ИНОЯЗЫЧНОГО ОБУЧЕНИЯ В РОССИЙСКОЙ ИМПЕРИИ ХVIII ВЕКА - ПЕРВОЙ ПОЛОВИНЫ ХІХ ВЕКА
}

\begin{abstract}
INTEGRATIVE APPROACH TO
THE THEORETICAL CONCEPTUALIZATION

OF THE FORMATION OF TEXTBOOKS

FOR FOREIGN LANGUAGE TEACHING

IN THE RUSSIAN EMPIRE OF THE XVIII CENTURY - FIRST HALF OF XIX CENTURY
\end{abstract}

\section{A. Kolobkova}

Summary: This article is devoted to the study of an integrative approach to theoretical conceptualization in the study of foreign languages, as well as the formation of educational literature for foreign language training in the Russian Empire. During the XVIII-first half of the XIX century, the Russian Empire did not yet have a unified methodology for foreign language education, so there were many different methodological approaches and attempts to create a complete program of foreign language education through the use of an integrative approach. This article explores the formation of foreign language learning methods in the Russian Empire. It is revealed that the integrated approach to teaching foreign languages allowed not only to raise the level of knowledge of students to a higher quality, but also contributed to the comprehensive development of the individual. Skills and techniques of foreign language teaching, which were formed in the XVIII century, served as the basis for modern theoretical conceptualization in the teaching of foreign languages. The reasons for introducing foreign languages (French, German, English, Italian) into the educational process by attracting foreign citizens as Tutors, teachers, lecturers, and educators as living native speakers are clarified. Textbooks, grammars, $A B C s$, and fiction in the original language contributed to the effective study of a foreign language in the Russian Empire.

Keywords: integrative approach, methodology, education, foreign languages, foreign language teaching, secular school, culture.

\author{
Колобкова Анастасия Анатольевна \\ К.n.н., доцент, Российский университет кооперации, \\ Москва \\ akolobkova@yandex.ru
}

Аннотация: Статья посвящена выявлению принципов интегративного подхода как концептуального понимания иноязычного обучения в Российской империи XVIII - первой половины XIX века, а также используемой при этом учебной литературы. В рассматриваемый временно́й период не было единой методологии иноязычного обучения, существовало множество разных методических подходов и попыток создать целостную программу иноязычного обучения. В данной статье автором исследуется генезис методики обучения иностранным языкам в России. Выявлено, что интегративный подход к преподаванию иностранных языков позволил не только поднять на более качественный уровень знания учащихся, но и способствовал всестороннему развитию личности. Навыки и приемы иноязычного обучения, сформировавшиеся еще в XVIII веке, послужили основанием для современной теоретической концептуализации в преподавании иностранных языков. В статье приводятся доводы привлечения к процессу обучения иностранным языкам (французскому, немецкому, английскому, итальянскому) иностранцев, носителей языка в роли гувернеров, преподавателей, лекторов, воспитателей. Учебники, грамматики, азбуки, художественная литература на языке оригинала способствовали результативному изучению иностранного языка в Российской империи.

Ключевые слова: интегративный подход, методика, образование, иностранные языки, иноязычное обучение, светская школа, культура.

собствующих наиболее эффективному изучению иностранных языков. Разработана концепция иноязычного обучения от начальной школы до высших учебных заведений. Четкость и методическая выверенность в современной педагогике существует благодаря достижениям педагогов-предшественников.

Некоторые современные методики иноязычного обучения были разработаны еще в XVIII веке. Целью статьи является анализ интегративного подхода к теоретической концептуализации формирования учебной литературы для иноязычного обучения в Российской империи 
XVIII века - первой половины XIX века, который послужил фундаментом для дальнейшего развития методик иноязычного обучения, которые использует современная педагогическая наука.

\section{Основная часть}

Россия не испытывала прямого влияния западной культуры вплоть до принятия христианства на Руси. Необходимость в переводах церковных книг с греческого языка положило начало филологическому образованию. Со временем, необходимость в образованных людях привела к тому, что в первой трети XVII века было открыто учебное заведение совершенно нового типа - Киево-Могилянская школа (в начале XVIII века была уже академией). В самом начале, сразу после открытия, в учебном заведении изучали только лишь греческий, латинский, славянский языки, но, начиная с XVIII века, учебные планы были дополнены изучением новых европейских языков - немецкого и французского. С начала XVIII века древние и западноевропейские языки преподаются во многих учебных заведениях России, преимущественно в тех, которые включали в учебный цикл предметы гуманитарной направленности, например, в лицеях и гимназиях.

В конце XVII века постепенно начинает меняться русская школа, утрачивая характер и качества исключительно сословного учреждения, предназначением которого была подготовка духовенства. В этот период открываются новые по своему характеру и назначению учебные заведения. Среди них школа Немецкой слободы, школы при Андреевском и Чудовом монастырях, школа Симеона Полоцкого. Именно заслугой Симеона Полоцкого является создание в 1632 году Славяно-греко-латинской академии - знакового для России учебного заведения. Безусловно, обучение в академии было в большей мере ориентировано на изучение классических древних языков и аспектов античной культуры, само название учебного заведения говорит именно об этом [12].

Создаются новые школы, но уже с элементами светского подхода к обучению. Помимо детей духовенства, в таких школах учились дети бояр, князей и дворян, поэтому спектр изучаемых наук со временем увеличивался, отходя от привычных богословских предметов. В школах кроме физики, математики, юриспруденции большое количество учебных часов было отдано на изучение латыни. Первыми, основными учебными книгами стали издававшийся несколько раз большим тиражом «Букварь» Кариона Истомина, «Грамматика» Мелетия Смотрицкого, «Считание удобное», «Учение и хитрость ратного строя», труды Симеона Полоцкого. Создание новых школ и усиление в них элементов светской культуры не находило поддержки среди представителей духовенства, хотя школы, по-прежнему, оставались в их руках.
B XVII веке латинский и греческий языки преподавали в греко-латинских школах, где обучали будущих переводчиков и педагогов, а с начала XVIII века эти языки изучаются уже довольно широко. Средними учебными заведениями, где учащиеся могли получить в том числе и иноязычное образование, были лицеи и гимназии.

В этих учебных заведениях не только изучались латинский, греческий, немецкий и французский языки, но и создавались все условия для нравственного и культурного становления человека. Важно было в процессе обучения не только выучить новый язык, но и освоить новый подход к миропониманию, развить в себе навыки, которые могли стать полезными в этой новой эпохе. Уже тогда закладываются основы интегративного подхода для эффективного изучения иностранного языка путем соединения разных методик обучения [5].

В первой четверти XVIII века, вследствие деловых и дипломатических контактов России с Европой, возникает необходимость в квалифицированных специалистах инженерной, научной, педагогической областях знаний [9, с. 123]. Петр I издает указ в 1701 году, который положил начало светскому школьному образованию, и речь шла не о реформировании, а о создании нового по форме и по содержанию образования. М.В. Богуславский отмечает, что совершенно новые подходы в сфере обучения и воспитания нельзя трактовать как реформы, реорганизацию, а, скорее, как попытку создать, подвести основу под систему российского образования. Ученый подчеркивает, что «...радикальные реформы, начатые Петром I, привели к кардинальной трансформации педагогических традиций» [1]. Таким образом, в XVIII столетии в российской империи появляются школы с элементами светского образования, были разработаны и внедрены совершенно новые подходы и основы обучения и воспитания, предприняты попытки создания государственной системы в сфере образования. Тогда, в 60-70-е годы создаются новые учебные заведения, целью и предназначением которых было провозглашено воспитание поколений «новой породы людей» - образованных и добродетельных. В каждом губернском городе открываются училища для детей мещан - четырехклассные училища, а в уездных городах - двухклассные. Для дворян существовали кадетские корпуса и частные пансионы, открывались школы для купечества.

В связи с усилением международных отношений России с европейскими государствами, а также по причине преобразовательной внутренней политики возросла потребность в знании и владении иностранными языками. Практиковалось изучение иностранных языков путем постоянного общения учащихся с носителями языка. «Молодых людей отправляли за границу, где они овладевали иностранными языками, приобщались к культуре, проникались желанием перенести европей- 
ские порядки в Россию. В целом, образование в открывавшихся светских школах носило характер приобретения профессиональных знаний. Воспитанию придавали второстепенное значение, это не входило в задачу нового времени» [8]. Иноязычное образование было направлено не только на изучение языка как такового, но и на духовное, нравственное совершенствование учащегося на почве своеобразного дискурса в рамках как родной культуры, так и культуры страны изучаемого языка. Целью изучения иностранных языков в российских учебных заведениях в этот период становится не только подготовка квалифицированных специалистов, например, переводчиков, толмачей, но и развитие системы ценностей человека, его мышления, духовности, - формирование личности. Исследователи в сфере истории педагогики и лингводидактики, в частности М.Н. Ветчинова, подчеркивают: «Наблюдая за тем, какие способы выражения мыслей существуют в родном и иностранных языках, мы формируем представление об окружающей действительности своей и иноязычной культуры. На основе этого языкового сознания формируется мышление человека» [3]. Изучение иностранного языка увеличивало словарный запас учащегося, помогало лучше понять корни некоторых слов в родном языке.

В эпоху Екатерины II в Россию проникают западноевропейские педагогические идеи. «Екатерина II, поклонница философов-энциклопедистов, склонялась к просвещению общечеловеческому, что на языке того времени значило «просвещение французское». И, даже несмотря на страх перед французской революцией, всё русское образованное общество заговорило пофранцузски» [6].

Инициативой Российского просветителя XVIII века И.И. Бецкого в 1764 году было основано учебное заведение, известное под названием Институт благородных девиц, что положило начало системному женскому образованию в Российской империи. Программы обучения в институтах благородных девиц также были разработаны Иваном Ивановичем Бецким в рамках образовательной политики Екатерины II [7]. По окончанию института девушки должны были уметь шить, вышивать, читать, писать и, что очень важно, понимать иностранную речь. Также в течение 12 лет девушки учили иностранные языки - преимущественно французский и немецкий.

Для того, чтобы ученицы не только лучше усваивали изучаемый иностранный язык, но и изучали культуру разных стран, был разработан новый подход, достаточно эффективный и результативный, охватывающий все стороны жизни обучающихся. В современном понимании это интегративный подход. Данный комплекс методов, по мнению О.В. Борщевой, направлен на формирование общего уровня культуры учащихся, а также развитие целостного мировоззрения «благодаря не только инте- грированию дисциплин, но и слиянию методов, форм и организации учебного процесса» [2]. Ученицы института благородных девиц свободно владели иностранными языками, так как для их обучения приглашались преподаватели из разных стран, носители языка, которые разговаривали с девушками только и исключительно на своем родном языке, тем самым вынужденно погружая в иноязычную языковую среду. Чтобы ученицы грамотно не только разговаривали, но и писали на иностранном языке, для обучения использовались учебники. Одним из первых и самых известных изданий учебников по французскому языку того времени стала книга ученого, переводчика и преподавателя В.Е. Теплова «Новая француссская грамматика сочиненная вопросами и ответами». Популярным стало учебное пособие А. Лави «Французская азбука» (1767). «Ученицы имели настолько прекрасное произношение, что иностранцы, присутствовавшие на институтских театральных постановках, восхищались уровнем владения французского языка. В свою очередь, Н.П. Черепнин приводит свидетельство того, что однажды англичанин Сохе, побывавший в Смольном институте благородных девиц, был изумлен чистейшей речью и произношением старших девочек воспитанниц в постановке «La servant maitresse», и младших - в пьесе «L'Oracle».

Для того, чтобы в ученицах развить художественных вкус, в качестве обучения иностранному языку применялось чтение оригинальной, художественной литературы. В этой связи Т.В. Каленцова пишет: «Практическое владение иностранными языками преследовало и другую цель - развитие мышления, активизацию познавательной деятельности, формирование навыков самообразования. Особая роль при обучении иностранным языкам отводилась чтению оригинальной литературы» [7]. Чтение художественной литературы на иностранном языке не только раскрывало в полном объеме красоту другого языка, но и знакомило с культурой разных стран. «Отбор литературных источников по содержанию способствовал развитию творческих, нравственных и эстетических начал личности» [7].

Одной из форм обучения была вышеупомянутая организация театральных постановок. Поскольку пьесы ставились на французском, ученицы имели возможность демонстрировать великолепие своего произношения. Вместе с тем Т.В. Каленцова отмечает следующее: «в 1775 году девушек помимо французского и немецкого, обучают итальянскому языку, чтобы воспитанницы исполняли произведения музыкального искусства именно на этом языке» [14]. Интегративный подход при обучении иностранному языку является соединением принципа культуросообразности и принципа диалога культур. Несмотря на совершенно явные успехи в иноязычном обучении Комиссия народных училищ в 1783 году, проверяя эффективность деятельности учебных заведений 
для девочек, выявила некоторые недостатки в преподавании иностранных языков [14]. По всей вероятности, Комиссия связала это с отсутствием единого подхода к иноязычному обучению, что в дальнейшем способствовало разработке методических рекомендаций для учителей немецкого и французского языков. Новый план обучения должен был уже совместить как фонетические, лексические, грамматические навыки, так и навыки разговорной речи в совокупности со специально разработанной системой упражнений и заданий.

Известными и широко распространенными учебниками в тот период были французские азбуки, например, «Азбука французская новая» (1789 год) - модификация «Азбуки» (1767), а также «Наставление как по-французски правильно читать и произносить» Якоба Сигезбека [10]. Учебники постоянно менялись и совершенствовались. Ученый С.В. Власов анализирует: «Скрытая полемика с малополезными в повседневной жизни «Французской азбукой» Лави и с «Французским букварем», изданным Вейтбрехтом и Шнором в 1778 г., содержится в «Новом французском букваре» известного переводчика и книгоиздателя П.И. Богдановича» [4].

Появление пособий по изучению немецкого языка происходило неравномерно. Какое-то время для изучения немецкого языка использовались учебники, применяемые в школах Германии. Многие грамматики того времени носят компилятивный характер. Например, «Немецкая грамматика» М. Шванвитца (1730) или «Немецкая грамматика, из разных авторов собрана и российскою юности в пользу издана от учителя немецкой гимназии». Отмечая заслуги преподававшего немецкий язык в Московском университете кандидата теологии Франциска Гельтергофа, К.А. Филиппов заключает: «В целом, «Немецкая грамматика» Фр. Гельтергофа принадлежит к числу наиболее успешных грамматик немецкого языка в России, она выдержала четыре издания в XVIII в. $(1770,1775,1784,1791)$ и пользовалась заслуженным успехом в российском обществе в последующие годы» [13]. Следует добавить, что начиная со второго издания 1775 года учебник содержал и хрестоматию произведений немецких авторов.

Наряду с существованием немецких и французских пособий во второй половине XVIII века, в России появились первые англоязычные учебники. В то время английский язык уступал по популярности французскому и немецкому. Интерес к нему вырос в результате активизации русско-английских экономических, политических и культурных контактов. Среди образованных людей английский не был модным, изучение английского языка носило скорее совершенно прагматичный характер. Автором первого в России учебника по английскому языку (1766 год) был Михаил Пермский. Его учебник - «Практическая английская грамматика», был переводом не- известного английского оригинала. В этот период были изданы и другие учебники П. Жданова - «Новое руководство в английском языке» и «Руководство к английскому языку», В. Кряжева - «Английская грамматика с прибавлением разговоров», И. Грузинова - «Английская грамматика», а также разговорник И.Ф. Вегелина - «Новые английские и российские разговоры». В этот период было создано несколько двуязычных словарей, в том числе П. Жданова. «При анализе текстов учебников обращает на себя внимание следующий факт: хотя большинство из перечисленных пособий названы «Грамматиками», в современном смысле слова они таковыми не являются, поскольку обобщают материал, выходящий далеко за пределы данного раздела языкознания. Подобное несоответствие объясняется, на наш взгляд, несовпадением современной лингвистической терминологии с системой терминов, принятой в России в рассматриваемый период» [11]. И, действительно, слово «грамматика» в то время толковалось как наука о языке, и именно так назывались учебники по иностранным языкам.

В начале XIX века основными учебными заведениями государства Российского, имеющими в учебных планах циклы предметов гуманитарной направленности, в том числе, курсы современных европейских языков, были лицеи и гимназии. В конце XVIII, начале XIX века для изучения, например, французского языка наиболее популярным был учебник И.Ф. Вегелина «Новый методический способ учиться хорошо читать, для употребления обучающихся французскому языку». Не меньшей популярностью пользовался учебник В.Е. Теплова - «Новая францусская грамматика сочиненная вопросами и ответами», которое в середине XVIII века было наиболее востребованным для обучения французскому.

Большое внимание изучению иностранного языка уделялось в отечественных гимназиях. Целью гимназий было подготовить ученика к поступлению в университет. Ввиду того, что первые российские университеты были ориентированы на Запад, приглашались преподаватели - иностранцы, которые часто плохо владели, или не владели совсем русским языком, именно в этой связи свои лекции они читали, преимущественно, на немецком, французском языках, а также - на латыни. Без хорошего знания иностранного языка было очень сложно учиться в университете. По этой причине в гимназиях очень внимательно относились к изучению иностранных языков. Приоритетным было также изучение культуры других народов, что влияло на становление индивидуальности. В программах обучения особо важное место занимало изучение классических древних языков - греческого и латинского, а также чтение литературных памятников античности, что, в свою очередь, способствовало развитию логического мышления, памяти, воображения. Основной целью изучения античной художественной литературы было воспитать лич- 
ность на ставших классическими образцах, примерах патриотизма и высокой нравственности. М.Н. Ветчинова отмечает: «Обучение древним языкам четко ориентировалось на развитие речи учащихся. Предполагалось, что культура речи ведет к культуре мышления. Работа над точностью и ясностью выражения мыслей связывалась с упорядочиванием самих мыслей, более глубоким пониманием сущности явлений. Методика преподавания древних языков в гимназии направлялась на умственное развитие гимназистов: они сопоставляли формы слов, их отношение друг к другу, упражнялись в применении различных грамматических средств» [3]. В изучении иностранного языка использовался интегративный подход, который включал в себя разные методики преподавания - изучение грамматики, общение с носителями иностранного языка, чтение художественной литературы, постановка пьес на языке оригинала. Еще одним способом достичь наиболее результативного изучения иностранного языка является метод заучивания текста, именно это подчеркивает М.Н. Ветчинова: «Особое значение отводилось развитию механических форм памяти - заучиванию наизусть отдельных отрывков, прочитанных поэтических и прозаических произведений. Для обучения иностранному языку использовались связные тексты хрестоматийного характера и подлинники европейской художественной литературы» [3]. Интегративный подход в обучении иностранным языкам помогал развить личностные качества учащегося, качества высокой нравственности, прививая чувство долга, ответственности, такой способ обучения формировал личность, свободную от стереотипов, свободную в выборе действий.

\section{Зак^ючение}

Анализ формирования учебной литературы для иноязычного обучения в Российской империи XVIII - первой половины XIX века показал, что в обучении использовались иностранные, а также отечественные учебники, которые постоянно совершенствовались. На примере французских, немецких, английский учебников можно проследить, как со временем общие разговорники заменяются сложными грамматическими пособиями. Для изучения иностранного языка использовались не только учебники, но и художественная литература.

Внедрение интегративного подхода при формировании учебной литературы для иноязычного обучения подразумевало сочетание разных методов, форм и организации учебного процесса. Были задействованы разные принципы интегративного подхода при изучении иностранных языков, как пример, принцип культуросообразности, а также принцип ориентации на саморазвитие, на самообразование, принцип диалога культур.

\section{ЛИТЕРАТУРА}

1. Богуславский М.В. Реформы российского образования XIX-XX вВ. Как глобальный проект // Вопросы образования. 2006. №3. С. 5-20.

2. Борщева О.В. (труктура интегративного подхода к обучению иностранному языку // Педагогика и психология образования. 2011. №1. С.5-8.).

3. Ветчинова М.Н. Иноязычное образование в гимназиях России в XIX веке // Ученые записки. Электронный научный журнал Курского государственного университета. 2006. №2. URL: https://cyberleninka.ru/article/n/inoyazychnoe-obrazovanie-v-gimnaziyah-rossii-v-xix-veke (дата 0бращения: 23.05.2020).

4. Власов С.В. Особенности начального обучения французскому языку по французским букварям, изданным в России во второй половине XVIII века // Отечественная и зарубежная педагогика. 2015. №1 (22). С.18-28.

5. Гусевская Н.Ю. Иноязычное образование как историко-образовательный феномен // Ученые записки ЗабГУ. Серия: Педагогические науки. 2011. №5. С.31-34.

6. Демков М.И. История русской педагогики. Новая русская педагогика (XVIII). - М.: 1910. 627 с.

7. Каленцова Т.В. Иностранные языки в образовательном процессе институтов благородных девиц второй половины XVIII B. // Russian Journal of Education and Psychology. 2012. №11. URL: https://cyberleninka.ru/article/n/inostrannye-yazyki-v-obrazovatelnom-protsesse-institutov-blagorodnyh-devits-vtoroypoloviny-xviii-v (дата обращения: 17.05.2020).

8. амызина А.В. Основные вехи иноязычной подготовки в отечественном образовании XVIII начала XX вв. // Наука. Инновации. Технологии. 2007. №50. С.43-47.

9. Колобкова А.А. К вопросу об изучении французского языка в Российской империи в середине XVIII - начале XIX века // Ценности и смыслы. 2019. № 6 (64). С. 118-130.

10. Колобкова А.А. Учебные книги по французскому языку в России XVIII - первой половины XIX веков: монография / А.А. Колобкова. — Москва : Знание-М, 2020. - $96 \mathrm{c}$.

11. Сидорова 0.Г. Первые учебники английского языка, изданные в России // Антиномии. 2009. №9. С.538-550.

12. Соловова Е.Н., Пореченкова Е.А. Из истории развития филологического образования // Иностран ᄀные языки в школе. 2008. № 2. С. 9-16.

13. Филиппов К.А. Метатекстовые особенности немецких грамматик в россии XVIII века // Вестник Московского государственного лингвистического университета. Гуманитарные науки. 2019. №1 (817). С.328-341.

14. Черепнин Н.П. Императорское воспитательное общество благородных девиц. Исторический очерк. (1764 - 1915): в 3т. Т.1. Спб.: Государственная типография, 1914.620 c. 